\title{
CETP kompozitlerin ağaç matkabıyla delinme performanslarının deneysel incelenmesi
}

\author{
Experimental investigation of CETP composites with wooden drilling \\ performance
}

\author{
Murat Koyunbakan",* (D), Ali Ünüvar² ${ }^{2}$, Volkan Eskizeybek ${ }^{3}$, Ahmet Avcı' ${ }^{4}$ \\ ${ }^{1}$ Kütahya Dumlupınar Üniversitesi, Makine Mühendisliği Bölümü, 43500, Kütahya, Türkiye \\ ${ }^{2}$ İstanbul Ticaret Üniversitesi, Endüstrivel Tasarım Bölümü, 34840, İstanbul, Türkive \\ ${ }^{3}$ Çanakkale Onsekiz Mart Üniversitesi, Malzeme Bilimi ve Mühendisliği Bölümü, 17020, Çanakkale, Türkiye \\ ${ }^{4}$ Necmettin Erbakan Üniversitesi, Biyomedikal Mühendisliği Bölümü, 42090, Konya, Türkiye
}

\begin{abstract}
Özet
Cam elyaf takviyeli polimer (CETP) kompozit malzemeler sahip oldukları üstün özelliklerinden dolayı yeni ve önemli mühendislik malzemeleridir. Mekanik özellikleri, rijitlik/ağırlık oranlarından dolayı özellikle hafiflik istenilen mühendislik yapılarında vazgeçilmez yapısal malzemelerdir. Bu sayede CETP kompozit malzemeler endüstride sıklıkla kullanılmaktadır. Delme işlemi endüstride CETP kompozitlerin montajı için gerekli deliklerin elde edilmesinde en önemli prosestir. Delik kalitesine kesme parametrelerinin yanı sira matkap geometrisinin etkisi de ele alınmalıdır. Bu çalışmada, fark $\iota_{\Perp}$ kesme parametreleri (kesme hizı, ilerleme) ve matkap geometrileri (farklı çaplar) ile delme işlemi gerçekleştirilmiştir. İtme kuvveti ile giriş ve çıkış yüzeyleri için deformasyon faktörü sonuçları elde edilmiştir. Ayrıca kesme parametrelerinin sonuçlara olan etkilerinin belirlenmesi için Taguchi metodu ve varyans analizi kullanılarak analiz yapılmıştır. Taguchi analizi için $\mathrm{L}_{9}\left(3^{13}\right)$ ortogonal deney tasarımı seçilmiş ve cevap tabloları kullanılmıştır. İtme kuvveti ve çıkış deformasyon faktörü için ilerlemenin, giriş deformasyon faktörü içinse matkap çapının daha etkin parametre oldukları tespit edilmiştir. Sonuçlar, CETP kompozit malzemelerin delinmelerinde bu yaklaşımın etkin bir şekilde uygulanabileceğini göstermiştir.
\end{abstract}

Anahtar kelimeler: CETP kompozit, Delme, İtme kuvveti, Deformasyon faktörü, Taguchi analizi, Varyans analizi

\section{Giriș}

Kompozit malzemelerin mühendislik alanında kullanılması gün geçtikçe yaygınlaşmaktadır. Çünkü bu malzemelerin özgül mukavemet, rijitlik, yorulma sınırı, hafifliği ve son şekline yakın üretilebilmesi ve kalıplanması gibi özellikleri oldukça iyidir [1]. Kompozit malzemelerin sahip olduğu bu özellikler onların işlenebilirlik özellikleri konusunda da yoğun çalışmalar yapılmasını gerektirmekte

\begin{abstract}
Glass fiber reinforced polymer (CETP) composite materials are new and important engineering materials due to their superior properties. Due to their mechanical properties, rigidity / weight ratio, they are indispensable structural materials, especially in engineering structures where lightness is required. Therefore, GFRP composite materials are commonly used in industry. Drilling is an important process for obtaining the holes which is necessary for the assemblies of GFRP in industry. In addition to drilling parameters, the impact of drill geometry on the hole quality should be considered. In this paper, drilling process was carried out with different cutting parameters (cutting speed, feed rate) and drill geometries (different diameters). The obtained the results of thrust force and deformation factor for exit/entrance surface. Taguchi method and analyze of variance (ANOVA) was also applied to determine the effects of cutting parameters on experimental results. L9 $\left(3^{13}\right)$ orthogonal experimental design was selected for analysis of Taguchi and response Tables was used. Besides the cutting parameters, the impact of drill geometry on the results are also discussed. It is obtained that feed rate governs the thrust force and exit deformation factor; however, the entrance deformation is driven by the drill bit diameter. The results show that this approach has been demonstrated can be used effectively for drilling of GFRP composite materials.
\end{abstract}

Keywords: GFRP composite, Drilling, Thrust force, Deformation factor, Analyzes of Taguchi, Analyzes of variance.

ve pek çok araştırmacı bu konuda çalışmaktadır [2]. Kompozit malzemeler her ne kadar son şekli verilerek üretilseler de yine de bazı talaşlı imalat işlemlerine tabi tutulmaktadırlar. $\mathrm{Bu}$ işlemlerden en fazla kullanılan yöntemse delme işlemidir. El Sonbaty ve diğ. [3], küçük bir motorlu uçakta 100000 'in üzerinde delik bulunduğunu belirtmektedir. Endüstride kompozit elemanlar yaygın olarak matkapla konvansiyonel biçimde işlenmektedir [4].

\footnotetext{
* Sorumlu yazar / Corresponding author, e-posta / e-mail: murat.koyunbakan@dpu.edu.tr (M. Koyunbakan)

Geliş / Recieved: 23.11.2020 Kabul / Accepted: 08.03.2021 Yayımlanma / Published: 27.07.2021

doi: $10.28948 /$ ngmuh. 830262
} 
Kompozit malzemelerde delme işlemi yapılırken karşılaşılan bazı problemler vardır. Bunların başında tabaka ayrılması ve elyaf sıyrılması gibi problemlerdir. Bu hasarlar, özellikle fiber takviyeli tabakalı kompozitlerde fiber yönüne ve tabaka simetrisinden kaynaklanan anizotropiden dolayı ortaya çıkmaktadır [5-7]. Tabaka ayrılması, iki komşu fiber tabakası arasında yer alan reçinece zengin bölgenin özellikle kalınlık yönünde yüklere maruz kaldığında tabakaların birbirinden ayrılması olarak ortaya çıkan, tabakalı kompozitlerde rijitliğin hasar oluşumu ile birlikte ani düşmesine neden olarak yapının fonksiyonunu yitirmesine neden olan bir hasar tipidir. Tabaka ayrılması hasarı üzerine yapılan çalışmalarda itme kuvvetlerinin bu hasarın oluşmasında etkin rol oynadığı tespit edilmiştir [8,9].

Cam elyaf takviyeli epoksi kompozit malzemelerin delinmesinde delik kalitesini artırmak üzere pek çok çalışma yapılmaktadır. Bunlardan bazıları da matkap uç geometrisinin değişiminin delik kalitesine olan etkilerinin incelenmesi üzerinedir. Can ve Ünüvar [10], çalışmalarında farklı kesme parametrelerinin cam elyaf takviyeli kompozitlerin delinmelerinde meydana gelen itme kuvvetleri ile giriş ve çıkış deformasyonları üzerine olan etkilerini incelemişlerdir. Matkap çapını $6 \mathrm{~mm}$ olarak seçmişler ancak uç açılarının değişiminin sonuçlara olan etkisini araştırmışlardır.

Yapılan çalışmalarda farklı kesme parametreleri (kesme hızı, ilerleme), kesici türleri (HSS, karbür vb.), ve kesici takım geometrilerinin delik kalitesine olan etkileri incelenmektedir. Abrao ve diğ. [11], farklı matkap uçları ve kesme parametreleri kullanarak yapmış oldukları çalışmada kesme hızı ve ilerleme oranına bağlı olarak meydana gelen itme kuvvetlerini ve oluşan deformasyonu incelemişlerdir. Latha ve diğ. [12], cam elyaf takviyeli kompozit malzemelerin delinmesinde üç farklı matkap uç geometrisi kullanarak itme kuvvetine olan etkilerini araştırmışlardır. En uygun sonuçların kademeli matkapla delmede elde edildiğini belirtmişlerdir. Rakesh ve diğ. [13], dört farklı matkap ucu kullanarak meydana gelen itme kuvvetlerini incelemişlerdir. Matkap uçlarının geometrisinin oluşan itme kuvvetleri ve hasarla büyük ölçüde ilişkili oldukları anlaşılmıştır.

Son zamanlarda elyaf takviyeli polimer kompozit malzemelerin mekanik özelliklerinin geliştirilmesi için matris içerisine nano partiküller ilave edilmektedir. Bu nano kompozitlerin işlenebilirliği üzerine de bazı çalışmalar yapılmaktadır. Kaybal ve diğ., karbon nano tüp katkılı ve katkısız karbon elyaf takviyeli polimer kompozitlerde kesme parametrelerinin delaminasyon oluşumu üzerine etkilerini ve işlenebilirliğini incelemişlerdir. Tepki yüzey metodoloji kullanarak kesme parametrelerinin etkilerini incelemişlerdir. Taguchi yöntemini kullanarak kesme parametrelerin etki dereceleri araştırılmıştır. Karbon elyaf takviyeli polimer kompozitlerin delinmelerinde delaminasyonun en aza indirilmesi için düşük ilerleme hızının yüksek kesme hızıyla kombinasyonunun gerekli olduğunu belirtmişlerdir [14]. Kaybal ve diğ., karbon fiber nano kompozit malzemelerin özelliklerinin geliştirilmesi için matris içerisine bor nitrür nano partikül ilavesi yapılmış ve daha sonra delme performanslarını araştırmışlardır. Bor nitrür nano partiküllerinin takviyesi ile itme kuvvetleri artmış olmasına rağmen literatürün aksine deformasyon faktörü azalma eğilimi göstermiştir [15]. Köklü ve diğ. cam ve karbon elyaf takviyeli polimer kompozit malzemeler ile birlikte işlevsel olarak derecelendirilirmiş kompozit malzemelerin delinme performanslarını araştırmışlardır. Üç malzeme de delme sırasında meydana gelen itme kuvveti, deleminasyon, delik çapı ve yuvarlaklık açısından karşılaştırılmıştır. Kesme kenarında $90^{\circ}$ ve $110^{\circ}$ iki açıya sahip karbür matkap kullanılmıştır. Derecelendirilmiş kompozit malzemelerde deliğin çıkışındaki delaminasyon deliğin çıkışına yerleştirilen malzemeden etkilenmiştir [16]. Gemi ve diğ., mekanik özelliklerini daha önce belirledikleri çeşitli cam ve karbon elyaf dizileri ile filaman sargilı hibrit kompozit boruların işlenebilirlik özelliklerini incelemişlerdir. Farklı ilerleme ve devir sayılarında yapılan deneylerde $8 \mathrm{~mm}$ çapında parmak freze kullanılmış ve karbon katmanının iki cam katman arasında istiflenmesi işlenebilirlik açısından daha iyi performans göstermiştir [17].

$\mathrm{Bu}$ çalışmanın amacı CETP kompozit malzemelerin farklı çaplarda iğne uçlu ağaç matkaplar ile delinmesinde meydana gelen itme kuvveti ve giriş-çıkış yüzeylerinde oluşan deformasyonun matkap çapı ve işlem parametrelerinden ne yönde etkilendiğini incelemektir.

\section{Materyal ve metot}

\subsection{Kompozit levhaların üretilmesi}

Deney numunelerinin üretilmesinde vakum infüzyon yöntemi kullanılmıştır. Üretilen kompozit numunelerin kalınlıkları yaklaşık 2.5 mm'dir ve 12 tabakadan oluşmaktadır. Kompozit numunelerin üretilmesinde laminasyon reçinesi kullanılmıştır. Alana bağlı yoğunluğu $200 \mathrm{gr} / \mathrm{m}^{2}$ olan cam elyaf kumaşlar ile üretilen numunelerin ASTM D 3039 standardına uygun yapılan deneylerde elde edilen sonuçlar Tablo 1'de verilmiştir. Yeterli miktarda epoksi ve sertleştirici (kütlece \%25) tartılmıştır. Birbirine mekanik olarak karıştırıldıktan sonra 0.7 Bar vakum altında epoksinin cam elyaf kumaşları ıslatması sağlanmıştır. Daha sonra kompozit $50{ }^{\circ} \mathrm{C}$ 'de 1 saat, $90{ }^{\circ} \mathrm{C}$ 'de 1 saat ve $125^{\circ} \mathrm{C}$ 'de 4 saat olacak şekilde kürlenmiştir. Şekil 1'de vakum infüzyon ünitesi ve malzeme üretimi gösterilmiştir.

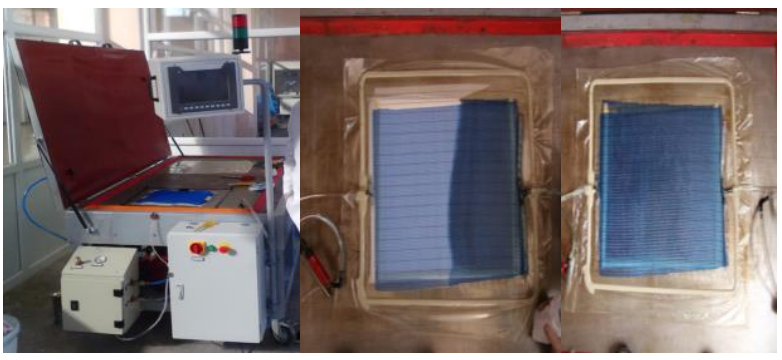

Şekil 1. Vakum infüzyon ünitesi ile malzeme üretimi

Tablo 1. Üretilen parçaların çekme testi sonuçları

\begin{tabular}{ccc}
\hline Malzeme & $\begin{array}{c}\text { Çekme Dayanımı } \\
(\mathrm{MPa})\end{array}$ & $\begin{array}{c}\text { Elastikiyet Modülü } \\
(\mathrm{GPa})\end{array}$ \\
\hline Cam Elyaf/Epoksi & 420 & 8 \\
\hline
\end{tabular}




\subsection{Delme işlemi}

Delme deneyleri Mazak Variaxsis 500 CNC işleme merkezinde gerçekleştirilmiştir. Matkap ucu olarak METABO firması tarafindan üretilen 34CrAl6 yüksek alaşımlı çelik malzemeden yapılan ağaç matkabı seçilmiştir. Literatürde kompozit malzemelerin işlenmesinde matkap geometrisinin delik kalitesine olan etkilerini inceleyen pek çok çalışma mevcuttur [1, 2, 18]. Yapılan çalışmalar incelendiğinde farklı uç açılarına sahip standart HSS ve karbür matkapların yoğun olarak kullanıldığ 1 görülmektedir. $\mathrm{Bu}$ çalışmalarda keskin uç geometrileri ile delik kalitesinde daha iyi sonuçların alındığı vurgulanmaktadır. Ağaç matkaplarının uç geometrileri metallerin işlenmelerinde kullanılan standart matkap uçlarından farklıdır. Kesme kenarları daha keskin olacak şekilde tasarlanmıştır. Bunun sebebi ağaç liflerini daha kolay kesebilmesi ve temiz bir delik yüzeyi oluşturması içindir. Ayrıca uç kısmındaki iğne ile merkezleme yapabilmektedir. Tabakalı kompozit malzemeler de yapı olarak ağaç malzemelere benzemektedirler. Metal malzemelerin delinmelerinde kullanılan standart matkap uçları ile yapılan bir takım delme işlemlerinde elyaf lifleri tam olarak kesilememekte bu yüzden delik giriş, çıkış ve iç yüzeylerinde çapak benzeri yapılar kalmaktadır. Bu ise hem delik kalitesi hem de görünüş açısından uygun olmayan bir durumdur. Cam elyaf takviyeli polimer kompozitlerin delinmelerinde farklı bir uç geometrisine sahip olan ağaç matkaplarının kullanımı bu tür problemler oluşturmayacağ1 düşünüldüğünden tercih edilmiştir. Seçilen matkapların görüntüleri Şekil 2'de verilmiştir. Deney numuneleri, yazarlar tarafindan geliştirilen bağlama düzeneği olan çelik levhalar arasında delinmiştir. Bu levhalar KISTLER marka 9257B model dinamometre üzerine bağlanarak itme kuvvetleri ölçülmüştür. Şekil 3 'te deneylerin yapıldığ 1 işleme merkezi görülmektedir.

Deneyler, farklı kesme parametreleri kullanılarak kuru ortamda yapılmıştır. Kesme parametreleri Tablo 2'de verilmiştir. Delme deneyleri üç kez tekrarlanmıştır. Delme esnasında her bir deney için yeni ağaç matkabı kullanılmıştır.
$\mathrm{Bu}$ nedenle matkap uç geometrisinde meydana gelebilecek aşınmaların deney sonuçlarına olan etkisi önlenmiştir. Deney tasarımında deney sayısını azaltmak ve en ideal sonuçların elde edilebilmesi amaciyla uygun olan deney parametrelerinin belirlenebilmesi için Taguchi metodu kullanılmıştır. $\mathrm{Bu}$ çalışmada, L9 $\left(3^{13}\right)$ ortogonal deney tasarımı seçilmiştir. Ortogonal tasarım ve elde edilen sonuçlar Tablo 3'te görülebilir. Bunun yanı sıra, bağımsız değişkenlerin (deney parametreleri) bağımlı değişkenler (ölçülen sonuçlar) üzerindeki etkilerinin belirlenebilmesi için varyans analizi (ANOVA) yapılmıştır.

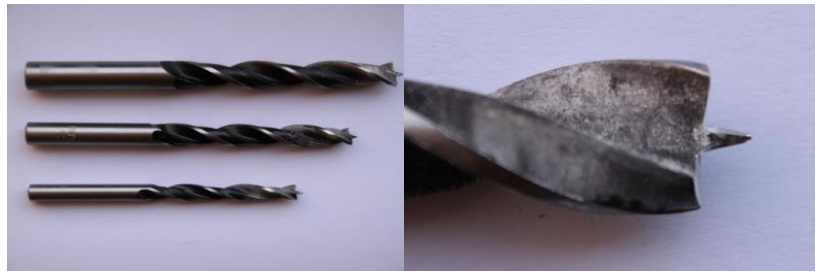

Şekil 2. Ağaç delme matkaplarının görünümü
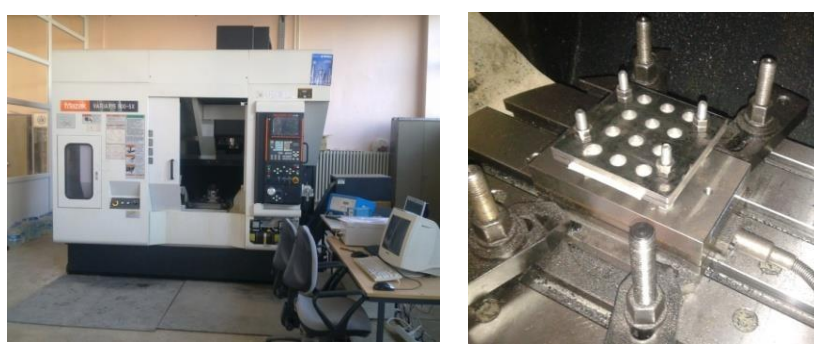

Şekil 3. İşleme merkezi ve deney düzeneği

Tablo 2. Deney parametreleri ve seviyeleri

\begin{tabular}{cccc}
\hline Deneysel Parametreler & Seviye 1 & Seviye 2 & Seviye 3 \\
\hline Kesme hızı (m/dk) & 50 & 67 & 90 \\
İlerleme (mm/dev) & 0.05 & 0.10 & 0.20 \\
Matkap çapı (mm) & 6 & 8 & 10 \\
\hline
\end{tabular}

Tablo 3. Ortogonal dizinin kullanıldığı deneysel tasarım ve cevaplar

\begin{tabular}{|c|c|c|c|c|c|c|c|c|c|}
\hline \multirow{2}{*}{$\begin{array}{c}\text { Deney } \\
\text { No }\end{array}$} & \multicolumn{2}{|c|}{ Kesme Hızı (m/dk) } & \multicolumn{2}{|c|}{ İlerleme (mm/dev) } & \multicolumn{2}{|c|}{ Matkap Çapı (mm) } & \multirow[t]{2}{*}{ İtme Kuvveti $(\mathrm{N})$} & \multirow{2}{*}{$\begin{array}{c}\text { Giriş } \\
\text { Deformasyon } \\
\text { Faktörü } \\
\end{array}$} & \multirow{2}{*}{$\begin{array}{c}\text { Çıkış } \\
\text { Deformasyon } \\
\text { Faktörü } \\
\end{array}$} \\
\hline & Kod & Gerçek & Kod & Gerçek & Kod & Gerçek & & & \\
\hline 1 & 1 & 50 & 1 & 0.05 & 1 & 6 & 21.34 & 1.100494 & 1.245671 \\
\hline 2 & 1 & 50 & 2 & 0.10 & 2 & 8 & 133 & 1.158684 & 1.419611 \\
\hline 4 & 2 & 67 & 1 & 0.05 & 2 & 8 & 81.13 & 1.137712 & 1.42664 \\
\hline 5 & 2 & 67 & 2 & 0.10 & 3 & 10 & 483.4 & 1.216756 & 1.517802 \\
\hline 6 & 2 & 67 & 3 & 0.20 & 1 & 6 & 275.77 & 1.19352 & 1.599345 \\
\hline 7 & 3 & 90 & 1 & 0.05 & 3 & 10 & 327.15 & 1.247579 & 1.502434 \\
\hline 9 & 3 & 90 & 3 & 0.20 & 2 & 8 & 537.11 & 1.160563 & 1.948156 \\
\hline
\end{tabular}


Tabakalı kompozit malzemelerin delinmelerinde giriş ve çıkış yüzeylerinde deformasyonlar meydana gelmektedir. Şekil 4'te oluşan mekanizma şematik olarak verilmektedir. Şekil de kırmızı elips içinde olan bölgelerde (Giriş ve çıkış yüzeylerindeki) deney numunesinin doğal renginden beyaza doğru renk değişimi şeklinde görülen hasarın tespit edilmesinde yaygın olarak kullanılan bir tahribatsız muayene tekniği olan deformasyon faktörünün belirlenmesi işlemi uygulanmaktadır. Maksimum hasar çapı ölçülerek matkap çapına orantılanması ile tespit edilmektedir.
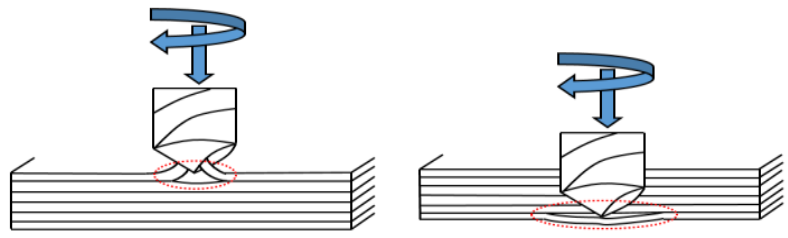

Şekil 4. Giriș ve çıkış yüzeylerinde oluşan deformasyonu meydana getiren mekanizmanın şematik resmi

$\mathrm{Bu}$ çalışmada delme işlemleri sonrası meydana gelen deformasyon faktörlerinin tespit edilmesi için Nikon Eclipse E100 optik mikroskop kullanılarak $100 \mu \mathrm{m}$ ölçekte optik görüntüler alınmıştır. Deformasyon faktörü delik etrafında oluşan matris hasarının matkap çapına oranı olarak tanımlanmış ve aşağıda verilen Denklem (1) ile hesaplanmıştır. Burada; $F_{D}$-Deformasyon faktörü, $D_{\max }$ Maksimum hasar çapı, D ise matkap çapıdır [2].

$$
F_{D}=\frac{D_{\max }}{D}
$$

Deformasyon faktörleri matkabın giriş ve çıkış bölgeleri için ayrı olarak tespit edilmiştir. Optik mikroskop kullanılarak $6 \mathrm{~mm}$ çap, $50 \mathrm{~m} / \mathrm{dk}$ kesme hızı ve 0.05 ilerleme değerlerinde elde edilen giriş ve çıkış bölgelerine ait görüntüler Şekil 5 'te verilmiştir.

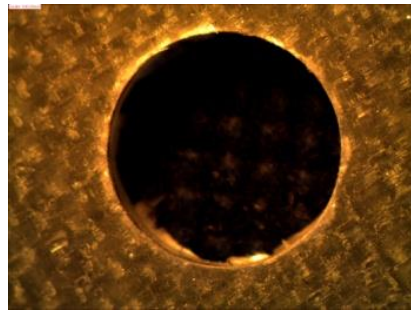

(a)

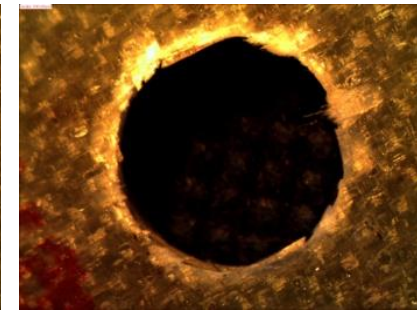

(b)
Şekil 5. Matkap ucunun a) giriş yüzeyi, b) çıkış yüzeyi

\section{Bulgular ve tartışma}

Kesme parametrelerinin polimer tabakalı kompozitlerin delinmelerindeki etkileri biliniyor olmakla birlikte matkap geometrilerisin etkisi için aynı şeyi söylemek zordur [19]. Bu çalışmada iğne uçlu 34CrAl6 yüksek alaşımlı çelik malzemeden yapılmış ağaç matkabının farklı çapları ve farklı kesme parametreleri kullanılarak bir takım deneyler gerçekleştirilmiştir. Deneyler kapsamında kesme hızı ve ilerlemeye bağlı olarak meydana gelen itme kuvvetleri ölçülmüştür. Elde edilen sonuçlar Şekil 6'da grafik olarak verilmiştir.

Ölçülen ve ortalamaları alınan kesme kuvvetlerinin, matkap çaplarına göre elde edilen grafik incelendiğinde kesme hızı ve ilerlemenin artışına bağlı olarak itme kuvvetlerinde artışlar olduğu gözlemlenmektedir. CETP kompozitlerin delinmelerinde kesme hızının etkisinin önemsiz olduğunu belirten birçok çalışma olmakla birlikte Khashaba ve diğ. [20], kesme hızının matkap ucu ön aşınmasına bağlı olarak itme kuvvetlerini arttırdığını bulmuşlardır. Bu çalışmada kullanılan ağaç matkaplarının tasarımlarından dolayı bir miktar ön aşınmaya maruz kalabildikleri ve bu nedenle kesme hızındaki artışa bağlı olarak itme kuvvetlerinin arttığı düşünülmektedir. En küçük itme kuvveti $6 \mathrm{~mm}$ çap, $50 \mathrm{~m} / \mathrm{dk}$ kesme hızı ve $0.05 \mathrm{~mm} / \mathrm{dev}$ ilerleme değerinde meydana gelmiştir. Ayrica matkap çapının büyümesi de itme kuvvetlerinde artışa sebep olmaktadir.

Kesme parametreleri ve matkap çapının deney numunelerinin giriş ve çıkış kısımlarında meydana getirdiği deformasyon faktörleri Şekil 7'de verilmiştir.

Meydana gelen deformasyon faktörü sonuçları incelendiğinde kesme hızı, ilerleme ve matkap çapının giriş ve çıkış deformasyon faktörleri üzerinde önemli etkiye sahip oldukları söylenebilir. Ağaç matkabının uç profili nedeni ile giriş deformasyonları çıkış deformasyonlarına göre daha az çıkmıştır. Ağaç matkabının uç profilinde merkezleme yapması için bir iğne uç bulunmaktadır. Bu iğne ucun ve kesme kenarlarının konumunun çıkış yüzeylerinde daha fazla baskı oluşmasını sağladığı düşünülmektedir. Oluşan bu baskı kuvveti sonucunda en alta bulunan tabaka ayrılmaya zorlanmakta bu nedenle giriş yüzeyinden daha fazla deformasyona uğramaktadır.

Kesme hızı, ilerleme ve matkap çapının artması deformasyon faktörlerini arttırmaktadır. Çıkış deformasyon faktörleri için Şekil 7b'deki sonuçlar incelendiğinde bir düzenli değişim görülememiştir.

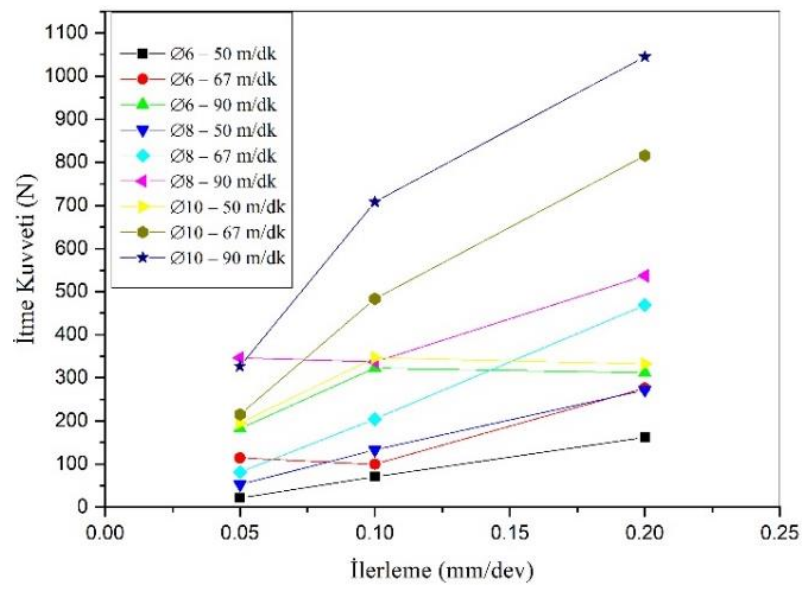

Şekil 6. İtme kuvvetlerinin ilerleme ve kesme hızına bağ $l_{1}$ değişimi 


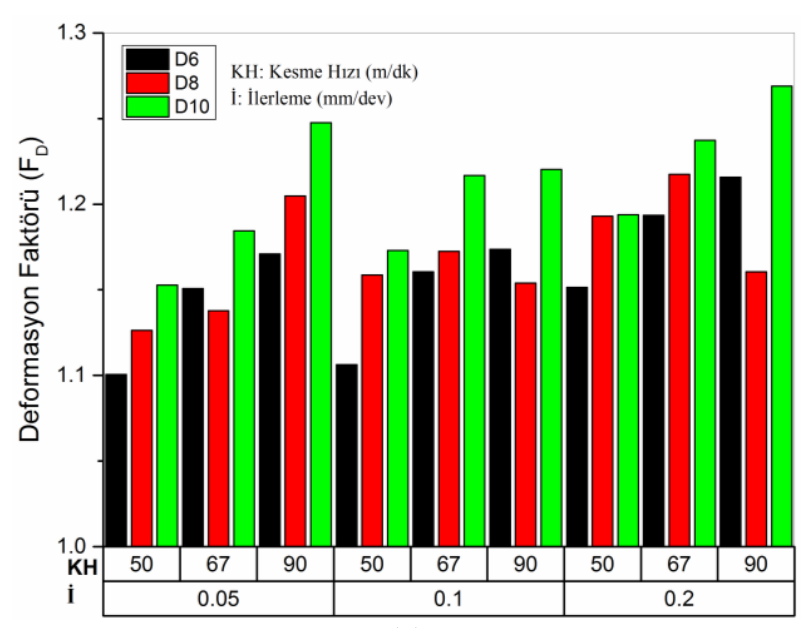

(a)

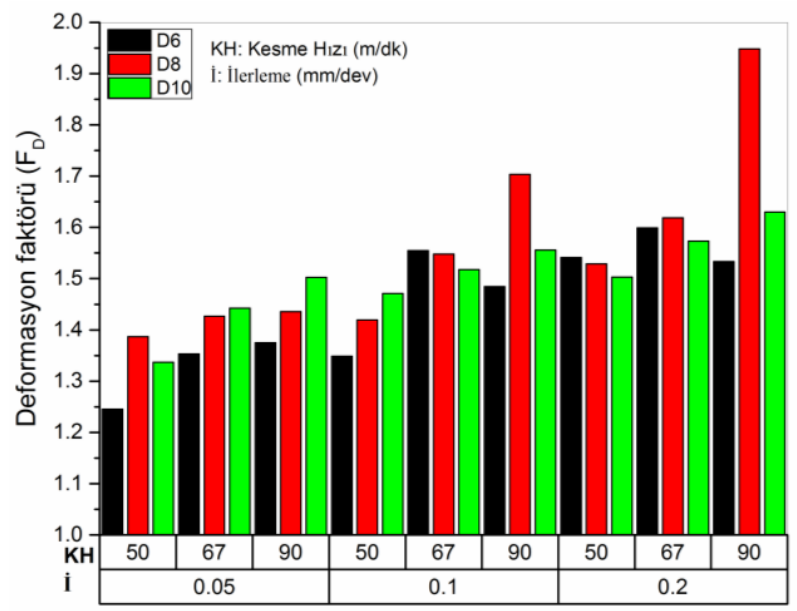

(b)

Şekil 7. Deformasyon faktörü değerleri a) giriş b) çıkış

Özellikle $8 \mathrm{~mm}$ çapındaki matkap için 0.10 ve 0.20 $\mathrm{mm} / \mathrm{dev}$ ilerleme parametrelerinde elde edilen deformasyon faktörleri beklenenden daha yüksek çıkmıştır. Bununla birlikte benzer değişim özellikle çıkış deformasyon faktörleri için diğer matkap çaplarında da bulunmuştur. $\mathrm{Bu}$ durumun özellikle ince tabakalı kompozitlerde delme işlemi esnasında azalan kalınlıkla birlikte artan eğilme gerilmelerinin kompozit malzemelerin son tabakalarında yarattığı ilave gerilmeler kaynaklı "patlatarak çıkma durumu" olduğu düşülmektedir. Bu durumun önlenebilmesi için delme işleminde prosesi etkilemeyecek şekilde kompozit malzemenin alttan desteklenmesi uygun olabilir.

Çalışmada, Dr. Genichi Taguchi tarafından geliştirilen Taguchi metodu kullanılmıştır. Sonuçları analiz edebilmek için $\mathrm{S} / \mathrm{N}$ oranı olarak bilinen bir istatistiksel performans ölçüsü kullanılmaktadır. Deneylerden elde edilen sonuçlar sinyal/gürültü oranına $(\mathrm{S} / \mathrm{N})$ çevrilerek değerlendirme yapılmaktadır. $\mathrm{S} / \mathrm{N}$ oranındaki $\mathrm{S}$ sinyal faktörünü, $\mathrm{N}$ ise gürültü faktörünü ifade etmektedir. Sinyal faktörü deneylerden alınan gerçek değeri, gürültü faktörü ise deney tasarımına katılamayan fakat deney sonucuna etki eden faktörleri ifade etmektedir. Gürültü kaynakları, elde edilmek istenen performans karakteristiklerinin hedef değerden sapmasına sebep olan tüm değişkenlerdir [21].
$\mathrm{S} / \mathrm{N}$ oranı, üç temel performans karakteristiğine göre saptanmaktadır. CETP kompozit malzemelerin delinmelerinde itme kuvvetlerinin ve deformasyon faktörünün az olması istendiğinden $\mathrm{S} / \mathrm{N}$ oranı için "daha küçük-daha iyisi" performans karakteristiği seçilmiştir. $\mathrm{S} / \mathrm{N}$ oranlarının hesaplanmasında kullanılan Denklem (2) aşağıda verilmiştir [22]. Deney tasarımı ve istatistiksel analizler, Taguchi metoduna göre Minitab 17 yazılımı ile yapılmıştır.

$$
\boldsymbol{S} / \boldsymbol{N}_{\boldsymbol{S B}}=\mathrm{\eta}=-10 \log \left[\frac{1}{n} \sum_{i=1}^{n} \mathrm{y}_{\mathrm{i}}^{2}\right]
$$

İtme kuvveti, giriş ve çıkış deformasyon faktörleri sonuçları için S/N oranları Tablo 4'te verilmiştir.

Ayrıca varyans analizi yapılmış ve kesme parametrelerinin sonuçlara olan katkıları tespit edilmiştir. Tablo 5'te $\mathrm{S} / \mathrm{N}$ oranı için cevap tablosu, Tablo 6'da $\mathrm{S} / \mathrm{N}$ oranı için varyans analizi tablosu görünmektedir. $\mathrm{S} / \mathrm{N}$ oranlarının her bir parametre için büyük olduğu değerler optimal faktör kombinasyonunu vermektedir [17]. Buna göre Tablo 6 incelendiğinde itme kuvveti için her üç parametrenin de birinci seviyeleri optimum olanlardır. Giriş deformasyon faktörü açısından kesme hızı ve ilerlemenin birinci seviyeleri matkap çapının ise ikinci seviyesi optimum faktörlerken çıkış deformasyon faktörü içinse her üçünün birinci seviyeleri optimum faktörler olarak tespit edilmiştir.

CETP kompozit malzemelerin ağaç matkabı ile delinmelerinde 3 seviye kesme hızı, ilerleme ve matkap çap1 için itme kuvvetlerinin minimum değerleri “daha küçük daha iyidir” kuralına göre $50 \mathrm{~m} /$ dak kesme hızı, 0.05 ilerleme ve $6 \mathrm{~mm}$ matkap çapında elde edilmiştir. İtme kuvvetlerine ilerlemenin etkisi \%43.59'la en fazladır. Giriş ve çıkış deformasyon faktörlerinin minimum değerleri “daha küçük daha iyidir" kuralına göre $50 \mathrm{~m} /$ dak kesme hızı, 0.05 ilerleme ve $6 \mathrm{~mm}$ matkap çapında elde edilmiştir. Giriş deformasyon faktörüne en büyük etkiyi \%55.54'le matkap çap1 yaparken, çıkış deformasyonuna en fazla etkiyi \%48.76 ile ilerleme yapmiştır.

Tablo 4. Sonuçlar için S/N oranları

\begin{tabular}{|c|c|c|c|}
\hline Deney & & $\mathrm{S} / \mathrm{N}$ oranlar & \\
\hline & $\begin{array}{c}\text { Itme } \\
\text { Kuvveti }\end{array}$ & $\begin{array}{c}\text { Giriş Deformasyon } \\
\text { Faktörü }\end{array}$ & $\begin{array}{c}\text { Çıkış Deformasyon } \\
\text { Faktörü }\end{array}$ \\
\hline 1 & -26.5839 & -0.83175 & -1.90806 \\
\hline 2 & -42.477 & -1.2793 & -3.04338 \\
\hline 3 & -50.4228 & -1.53956 & -3.5413 \\
\hline 4 & -38.1836 & -1.12065 & -3.08629 \\
\hline 5 & -53.6861 & -1.70407 & -3.6243 \\
\hline 6 & -48.8109 & -1.53659 & -4.07884 \\
\hline 7 & -50.2949 & -1.92136 & -3.53591 \\
\hline 8 & -50.1746 & -1.3911 & -3.43078 \\
\hline 9 & -54.6013 & -1.29337 & -5.79248 \\
\hline
\end{tabular}


Tablo 5. S/N oranı için cevap tablosu

\begin{tabular}{cccccccccc}
\hline & \multicolumn{3}{c}{ İtme Kuvveti } & \multicolumn{3}{c}{ Giriş Deformasyon Faktörü } & \multicolumn{3}{c}{ Çıkıs Deformasyon Faktörü } \\
\cline { 2 - 10 } Seviye & Kesme Hızı & İlerleme & $\begin{array}{c}\text { Matkap } \\
\text { Çap1 }\end{array}$ & $\begin{array}{c}\text { Kesme } \\
\text { Hızı }\end{array}$ & İlerleme & $\begin{array}{c}\text { Matkap } \\
\text { Çap1 }\end{array}$ & $\begin{array}{c}\text { Kesme } \\
\text { Hızı }\end{array}$ & İlerleme & Matkap Çapı \\
\hline 1 & -39.8279 & -38.3542 & -41.8565 & -1.21687 & -1.29125 & -1.25315 & -2.83092 & -2.84342 & -3.13923 \\
2 & -46.8936 & -48.7793 & -45.0873 & -1.45377 & -1.45816 & -1.2311 & -3.59648 & -3.36615 & -3.97405 \\
3 & -51.6903 & -51.2783 & -51.4679 & -1.53528 & -1.45651 & -1.72166 & -4.25305 & -4.47087 & -3.56717 \\
Fark & 11.86238 & 12.92417 & 9.611457 & 0.318411 & 0.165252 & 0.490558 & 1.422136 & 1.627454 & 0.834822 \\
Önem Derecesi & 2 & 1 & 3 & 2 & 3 & 1 & 2 & 1 & 3 \\
\hline
\end{tabular}

Tablo 6. $\mathrm{S} / \mathrm{N}$ oranı için varyans analizi tablosu

\begin{tabular}{ccccccccccccccc}
\hline Kaynak & SD & \multicolumn{4}{c}{ Kareler Toplamı } & \multicolumn{3}{c}{ Ortalama Kareler } & \multicolumn{3}{c}{ F-Oranı } & & \multicolumn{2}{c}{$\%$ Katk1 } \\
\hline & & IK & GDF & ÇDF & IK & GDF & ÇDF & IK & GDF & ÇDF & IK & GDF & ÇDF \\
\hline Kesme Hızı & 2 & 213.64 & 0.16 & 3.03 & 106.82 & 0.08 & 1.51 & 28.20 & 1.09 & 11.35 & 33.03 & 19.79 & 35.78 \\
İlerleme & 2 & 281.96 & 0.05 & 4.14 & 140.98 & 0.02 & 2.07 & 37.21 & 0.36 & 15.48 & 43.59 & 6.65 & 48.76 \\
Matkap Çap1 & 2 & 143.53 & 0.46 & 1.04 & 71.76 & 0.23 & 0.52 & 18.94 & 3.08 & 3.90 & 22.19 & 55.54 & 12.30 \\
Hata & 2 & 7.57 & 0.14 & 0.26 & 3.78 & 0.07 & 0.13 & & & & 1.17 & 18.01 & 3.14 \\
Toplam & 8 & 646.71 & 0.82 & 8.49 & & & & & & & & &
\end{tabular}

SD: Serbestlik derecesi, İK: İtme Kuvveti, GDF: Giriş Deformasyon Faktörü, ÇDF: Çıkış Deformasyon Faktörü

\section{Sonuçlar}

CETP kompozit malzemelerin ağaç matkabı ile delinmelerinde kesme parametrelerinin ve matkap çapının itme kuvveti ve giriş/çıkış deformasyon faktörleri üzerine etkilerinin incelendiği bir deneysel çalışma gerçekleştirilmiş ve bu parametrelerin sonuçlar üzerindeki etkilerinin analizi için Taguchi metodu kullanılmıştır. Sonuçlara ve analizlere dayalı olarak sonuçlar aşağıda sıralanmıştır.

1. Kesme hızı, ilerleme ve matkap çapının değişimi itme kuvvetlerini etkilemektedir. Her biri için değer arttıkça itme kuvvetleri de artmaktadır.

2. Taguchi metodu ile yapılan analizlerde "en küçük en iyidir" kuralına göre itme kuvvetleri açısından ilerleme \%43.59, kesme h1z1 \%33.03 ve matkap çapı \%22.19 etkili oldukları belirlenmiştir.

3. Giriş deformasyon faktörü açısından matkap çapı $\% 55.54$, kesme hızı \%19.79 ve ilerleme \%6.65 etkili oldukları belirlenmiştir.

4. Çıkış deformasyon faktörü açısından ise ilerleme $\% 48.76$, kesme hızı \%35.78 ve matkap çap1 \%12.30 etkili oldukları belirlenmiştir.

5. Tüm sonuçlar için en uygun kesme parametrelerinin ve matkap çapının $50 \mathrm{~m} / \mathrm{dk}$ kesme hızı, 0.05 ilerleme ve $6 \mathrm{~mm}$ matkap çapı olduğu tespit edilmiştir.

6. Taguchi analizi sonuçlar açısında uygun bir teknik olarak uygulanabilmiştir.

7. Çalışmanın doğruluğu daha fazla parametre ve seviye içerecek şekilde uygulanarak geliştirilebilir.

\section{Teşekkür}

$\mathrm{Bu}$ çalışmanın gerçekleşmesindeki katkılarından dolayı Türkiye Bilimsel ve Teknolojik Araştırma Kurumuna (TÜBİTAK) Proje No:113M789 teşekkür ederiz.

\section{Çıkar çatışması}

Yazarlar çıkar çatışması olmadığını beyan etmektedir.

\section{Benzerlik oranı (iThenticate): $\% 14$}

\section{Kaynaklar}

[1] V. A. Nagarajan, S. Sundaram, K. Thyagarajan, J.Selwin Rajadurai, and T.P.D Rajan., Measuring delamination severity of glass fiber-reinforced epoxy composites during drilling process. Experimental Techniques, 37, 66-73, 2013. https://doi.org/10.1111/ j.1747-1567.2012.00809.x

[2] E. Kilickap, Optimization of cutting parameters on delamination based on Taguchi method during drilling of GFRP composite. Expert Systems with Applications, 37, 6116-6122, 2010. https://doi.org/10.1016/ j.eswa .2010 .02 .023

[3] I. El-Sonbaty, U.A. Khashaba, T. Machaly, Factors affecting the machinability of GFR/epoxy composites. Compos Struct, 63(3-4), 329-338, 2004. https:// doi .org/10.1016/S0263-8223(03)00181-8

[4] C. C. Tsao, Experimental study of drilling composite materials with step-core drill. Materials and Design, 29, 1740 - 1744, 2008. https://doi.org/10.1016/ j.matdes .2008 .03 .022

[5] J. L. Deng, Introduction to grey system, Journal of Grey System, 1, 1-24, 1989. 
[6] N. Tosun, Determination of optimum parameters for multiperformance characteristics in drilling by using grey relational analysis. The International Journal of Advanced Manufacturing, 28, 450-455, 2006. https ://doi.org/10.1007/s00170-004-2386-y

[7] C.-J. Tzeng, Y.-H. Lin, Y.-K. Yang, M.-C. Jeng, Optimization of turning operations with multiple performance characteristics using the Taguchi method and Grey relational analysis. Journal of Materials Processing Technology, 209, 2753-2759, 2009. https://doi.org/10.1016/j.jmatprotec.2008.06.046

[8] J. P. Davim, P. Reis, A.C. Conceicao, Drilling fiber reinforced plastics (FRPs) manufactured by hand layup: influence of matrix (Viapal VUP 9731 and ATLAC 382-05). Journal of Materials Processing Technology, 155-156, 1828-1833, 2004-a. https://doi.org/10.1016/ j.jmatprotec.2004.04.173

[9] J. P. Davim, P. Reis, A.C. Conceicao, Experimental study of drilling glass fiber reinforced plastics (GFRP) manufactured by hand lay-up. Composites Science and Technology, 64, 289-297, 2004-b. https://doi.org/ 10.1016/S0266-3538(03)00253-7

[10] A. M. Abrão, J.C. Campos Rubio, P.E. Faria, J.P. Davim, The effect of cutting tool geometry on thrust force and delamination when drilling glass fibre reinforced plastic composite. Materials and Design, 29, 508-513, 2008. https://doi.org/ 10.1016/ j.matdes .200 7.01 .016

[11] B. Latha, V.S. Senthilkumar K. and Palanikumar, Influence of drill geometry on thrust force in drilling GFRP composites. Journal of Reinforced Plastics and Composites, 30, (6), 463-472, 2011. https://doi.org/ $10.1177 / 0731684410397681$

[12] P. K. Rakesh, I. Singh and D. Kumar, Drilling of composite laminates with solid and hollow drill point geometries. Journal of Composite Materials, 46,(25), 3173-3180, 2012. https://doi.org/10.1177/0021 9983 12436997

[13] H. B. Kaybal, A. Ünüvar, M. Koyunbakan, A. Avc1, A novelty optimization approach for drilling of CFRP nanocomposite laminates, The International Journal of Advanced Manufacturing Technology, 100, 29953012, 2019. https://doi.org/10.1007/s00170-018-28731

[14] H. B. Kaybal, A. Unuvar, Y. Kaynak, A. Avc1, Evaluation of boron nitride nanoparticles on delamination in drilling carbon fiber epoxy nanocomposite materials, Journal of Composite Materials, 54(2), 215-227, 2020. https:/ /doi.org/ 10. $1177 / 0021998319860245$

[15] U. Köklü, O. Demir, A. Avcı, A. Etyemez, Drilling performance of functionally graded composite: Comparison with glass and carbon/epoxy composites, Journal of Mechanical Science and Technology, 31 (10), 4703-4709, 2017. https://doi.org/10.1007/ s12 206-017-0916-4

[16] L. Gemi, U. Koklü, S. Yazman, S. Morkavuk, The effects of stacking sequence on drilling machinability of filament wound hybrid composite pipes: Part-1 mechanical characterization and drilling tests, Composites Part B: Engineering, 186, 1077871, 2020. https://doi.org/10.1016/j.compositesb.2020.107787

[17] T. N. Valarmathi, K. Palanikumar, B. Latha, Measurement and analysis of thrust force in drilling of particle board (PB) composite panels. Measurement, 46, 1220-1230, 2013. https://doi.org/10.1016/j.mea surement.2012.11.024

[18] A. Can, A. Ünüvar, Optımızation Of Process Parameters In Drilling Of Smc Composites Using Taguchı Method. Technical Gazette, 24, 2, 435-442, 2017. https://doi.org/10.17559/TV-20160103215256

[19] L. Gemi, S. Morkavuk, U. Koklü, D. S. Gemi, An experimental study on the effects of various drill types on drilling performance of GFRP composite pipes and damage formation. Composites Part B: Engineering,172, 186-194, 2019. https://doi.org/10. 1016/j.compositesb.2019.05.023

[20] U. A. Khashaba, I.A. El-Sonbaty, A.I. Selmy, A.A. Megahed, Machinability analysis in drilling woven GFR/epoxy composites: Part II - Effect of drill wear. Composites: Part A, 41, 1130-1137, 2010. https :// doi.org/10.1016/j.compositesa.2010.04.011

[21] F.Kara, O. Özbek, M. Kam, H. Saruhan, AISI 4140 1slah çeliğinin tornalanmasinda yüzey pürüzlülüğü ve titreşimin taguchi metodu ile optimizasyonu, II. International Academic Research Congress, pp. 11321140, Alanya/Antalya, Türkiye, 18-21 October 2017.

[22] A. Kaçal, and M. Gülesin, Determination of optimal cutting conditions in finish turning of austempered ductile iron using Taguchi design method. Journal Of Scientıfic \& Industrial Research, 278-283, 2011. 